\title{
Programa preventivo da cárie dentária baseado no controle mecânico da placa bacteriana em crianças, por meio da profilaxia profissional periódica. Resultados após 25 anos de acompanhamento
}

José Eduardo de Oliveira Lima*

\section{Resumo}

Objetivos: o objetivo deste trabalho foi verificar a incidência de cárie dentária em um programa de prevenção aplicado durante 25 anos em clínica particular. Metodologia: participaram desse programa 640 crianças de ambos os gêneros, na faixa etária de 3 a 15 anos de idade. $O$ programa foi baseado no controle mecânico da placa bacteriana dentária por meio da profilaxia profissional com jato de bicarbonato de sódio com uma periodicidade mensal. A incidência de cárie foi verificada por meio de exames clínicos durante as sessões de atendimento e radiográficos anualmente. A média de idade das crianças ao ingressarem no programa foi de 7,8 anos. Resultados: antes de ingressar no programa, as crianças apresentaram, em média, 5,3 faces cariadas, enquanto após o programa a média foi de 0,18. A incidência de cáries por ano antes do programa foi de 0,9 faces cariadas e durante o programa de 0,03 . O tempo de permanência das crianças no programa foi, em média, de 52,6 meses, e a média de faltas foi de 0,5 falta por ano. Esses resultados demonstram o sucesso do programa, principalmente por ter uma filosofia que procura o equilíbrio da biodiversidade da cavidade bucal, sem o risco de produzir efeitos colaterais indesejáveis. Conclusões: conclui-se, assim, que esse parece ser o caminho mais curto para resolver o problema da cárie dentária, ou seja, o controle mecânico da placa bacteriana dentária através da profilaxia profissional mensal, pois é um método de prevenção possível de ser aplicado em qualquer criança, independentemente de suas condições psicomotoras e sociais, e que proporciona a melhor relação custo-benefício, além de estar de acordo com os conceitos mais atuais de cárie e de seus fatores etiológicos. Em função da faixa etária das crianças, o programa é de suma importância para clínicas de Odontopediatria e Ortodontia.

Palavras-chave: Prevenção da cárie. Plano de prevenção da cárie. Profilaxia profissional periódica.

\section{INTRODUÇÃO}

Dentre os problemas de saúde bucal, a cárie dentária ainda constitui um dos maiores desafios da Odontologia ${ }^{18}$ e o seu entendimento como um processo multifatorial levou os pesquisadores à busca do desenvolvimento de inúmeros métodos para a sua prevenção, os quais objetivavam essencialmente o controle de possiveis fatores envolvidos no processo, assim como a tentativa de aumentar a resistência do hospedeiro.

\footnotetext{
* Professor associado do departamento de Odontopediatria, Ortodontia e Saúde Coletiva Faculdade de Odontologia de Bauru - USP.
} 
Diversas estratégias preventivas foram estabelecidas baseadas em critérios como contagem de microrganismos, controle de dieta, utilização de fluoretos, selamento de fóssulas e fissuras, dentre outras, sem que nenhuma delas atingisse níveis ideais de prevenção da cárie. Além disso, os possíveis efeitos colaterais provocados pela implementação dessas medidas deveriam ser avaliados. A ampla utilização do flúor nas últimas décadas, por exemplo, tem sido relacionada com o aumento do número de fluorose dentária, sugerindo o desenvolvimento e a ampliação de outras medidas preventivas ${ }^{21,27}$.

A placa dentária desempenha um papel importante no desenvolvimento da lesão de cárie e alguns autores, como Fejerskov ${ }^{10}$, consideram-na como a única causa do aparecimento dessa lesão, fazendo afirmações como: "a cárie dentária é uma doença multifatorial, mas a placa dentária é a única causa". Assim, o controle de placa é indispensável na elaboração de qualquer estratégia de prevenção, podendo ser obtido por meio químico ou mecânico. $\mathrm{O}$ uso constante de agentes químicos pode ocasionar diversas alterações do meio bucal, como descamação da mucosa, alteração do paladar ou modificação da microbiota bucal, levando ao surgimento de infecções oportunistas e, talvez, a algum nível de intoxicação sistêmica, desaconselhando esse método como procedimento de rotina.

O controle mecânico, por outro lado, pode ser implementado sem provocar efeitos colaterais significativos, podendo ser realizado pelo próprio indivíduo, através da escovação e uso do fio dental, ou por meio da profilaxia profissional. A escovação e uso do fio dental são medidas eficazes, bastante simples e amplamente utilizadas, porém, em se tratando de crianças, sua eficácia é diminuída devido às limitações psicomotoras próprias da idade, que dificultam o aprendizado e a realização adequada das técnicas ${ }^{18}$. Por outro lado, a profilaxia profissional tem se mostrado uma medida eficiente para a remoção de placa ${ }^{6,18}$, ganhando uma maior relevância dentro dos programas de prevenção à cárie dentáriai $^{3,4,5,15,18}$. A realização da profilaxia profissio- nal com uma maior frequência tem como intuito corrigir as deficiências da escovação ${ }^{18}$ no período em que o autocontrole se apresenta ineficiente.

Devido a resultados pouco satisfatórios durante 10 anos de experiência clínica, com aplicações de todos os métodos de prevenção preconizados até então e baseado nos trabalhos de Axelsson, Lindhe ${ }^{3}$; Axelsson, Lindhe e Wäseby ${ }^{5}$, iniciou-se em, 1982, um programa de prevenção da cárie dentária em clínica particular, cujo principal método preventivo foi o controle mecânico da placa bacteriana através da profilaxia profissional periódica.

O programa foi desenvolvido de modo a buscar a prevenção da cárie da maneira mais natural possível, proporcionando condições de equilíbrio da biodiversidade da cavidade bucal, potencializando a remineralização do esmalte no fenômeno de Des-Re.

O objetivo deste trabalho é apresentar os resultados obtidos durante os 25 anos de realização deste programa, verificando a incidência de cárie e possíveis relações e correlações entre os dados obtidos.

\section{MATERIAL E MÉTODOS}

Participaram desse estudo 640 crianças com idades entre 3 e 15 anos, de ambos os gêneros (318 do gênero masculino e 322 do gênero feminino) independentemente das condições psicomotoras e socioculturais - que procuraram a clínica para atendimento odontopediátrico.

Previamente ao início do programa, as crianças foram submetidas a um check-up inicial, por meio de exames clínicos e radiográficos, para detectar lesões de cárie e dentes anteriormente restaurados (índice CPO-S). Esses dados foram anotados em um odontograma que determinou a incidência de cárie por face e por ano antes da criança ingressar no programa, considerando a idade do paciente naquele momento como parâmetro, desconsiderando o $1^{\circ}$ ano de vida (incidência de cárie antes do programa / por face / por ano). Nesse momento, quando necessário, foi realizado tratamento 
curativo das lesões de cárie existentes, dando condições da criança iniciar o programa sem que nenhuma lesão deixasse de ser diagnosticada e tratada. A partir do check-up inicial, a incidência de novas lesões foi computada, determinando a incidência de cárie durante o programa.

O programa foi executado com uma estratégia preventiva única para todos os pacientes, independentemente de suas condições individuais quanto à experiência ou risco de cárie.

Durante sua permanência no programa, ou até a idade de 15 anos, as crianças receberam mensalmente uma profilaxia profissional com jato de bicarbonato de sódio. A profilaxia profissional foi precedida pela evidenciação da placa e complementada com uso do fio dental pelo próprio profissional, objetivando-se, assim, um controle de 100\% da placa. Outros métodos de prevenção - como selamento de fóssulas e fissuras, orientação da dieta, escovação, conscientização e motivação - foram agregados ao programa como métodos coadjuvantes, sem que, no entanto, houvesse nenhum tipo de controle de sua efetividade, isto é, não havia um protocolo de frequência do emprego desses métodos e nem um levantamento dos possíveis efeitos sobre a incidência de cárie. Assim, o único método de prevenção considerado indispensável e rigorosamente executado foi o controle mecânico de placa através da profilaxia profissional periódica mensal com o jato de bicarbonato de sódio.

Durante os 25 anos do programa, as sessões de atendimento foram realizadas por odontopediatras e as sessões de conscientização e motivação por THDs.

O diagnóstico de cárie foi realizado por meio de exames clínicos, durante as sessões de atendimento, e exames radiográficos anuais por meio de radiografias interproximais.

As lesões de cárie que ocorreram durante o programa foram anotadas no prontuário do paciente para computar a incidência de cárie por face/ano, assim como o número de faltas/ano. Caso o paciente tivesse mais que duas faltas durante o ano, era eliminado do programa e, se optasse por retornar ao mesmo, um novo check-up inicial era realizado, para dar início a um novo período de controle. Esse critério serviu para qualquer paciente que deixasse de frequentar o programa, independentemente do motivo.

Para a avaliação dos resultados, foi realizada análise estatística descritiva, utilizando os parâmetros de média e desvio-padrão para cada um dos aspectos abordados. Para avaliar a correlação entre as variáveis, foi utilizado o teste de correlação de Spearman, adotando-se nível de significância de 5\%.

\section{RESULTADOS}

Após análise dos dados, foram obtidos os resultados apresentados nas tabelas 1 a 4 e gráfico 1 .

\section{DISCUSSÃO}

O planejamento de qualquer estratégia preventiva deve levar em consideração a manutenção da qualidade de vida do paciente e de toda sua família, pois essa é uma condição de suma importância para se obter o sucesso neste tipo de programa, por se tratar de um atendimento de longo prazo. Assim, todos os métodos de prevenção propostos devem buscar os melhores resultados possíveis, porém sem alterar a qualidade de vida das pessoas envolvidas e sem correr o mínimo risco de provocar efeitos colaterais indesejáveis.

O grupo alvo para a implantação do programa foi de crianças na faixa etária de 3 a 15 anos de idade, tendo em vista a dificuldade relatada pelos pais em seguir as recomendações de profissionais quanto à escovação e controle da dieta, devido às limitações psicomotoras inerentes à criança em crescimento $\mathrm{e}$ desenvolvimento, que the conferem uma imaturidade, irresponsabilidade e falta de coordenação motora e tornam esses métodos pouco eficientes.

Diferentemente da fase de bebê, quando a alimentação pode ser melhor controlada, a criança maior de 3 anos encontra-se exposta a todo tipo de dieta cariogênica, seja na escola ou nas festas infantis, ou através dos meios de comunicação, que são 
TABELA 1 - Resultados de média, valor mínimo e valor máximo para as variáveis estudadas.

\begin{tabular}{|c|c|c|c|}
\hline variável & média & min. & $\max$ \\
\hline $\begin{array}{l}\text { idade da criança no início } \\
\text { do programa (em meses) }\end{array}$ & 94,18 & 30 & 204 \\
\hline $\begin{array}{l}\text { número de faces cariadas ao ingres- } \\
\text { sar no programa (por paciente) }\end{array}$ & 5,36 & 0 & 63 \\
\hline $\begin{array}{c}\text { número de faces cariadas detectadas } \\
\text { durante o programa (por paciente) }\end{array}$ & 0,18 & 0 & 7 \\
\hline $\begin{array}{l}\text { incidência de faces cariadas } \\
\text { antes do programa/ano }\end{array}$ & 0,9 & 0 & 24 \\
\hline $\begin{array}{c}\text { incidência de faces cariadas } \\
\text { durante o programa/ano }\end{array}$ & 0,03 & 0 & 1,5 \\
\hline $\begin{array}{l}\text { tempo (meses) de } \\
\text { permanência no programa }\end{array}$ & 52,68 & 12 & 156 \\
\hline número de faltas/ano & 0,54 & 0 & 2,8 \\
\hline
\end{tabular}

TABELA 3 - Distribuição das crianças por superfícies cariadas após o início do programa.

\begin{tabular}{ccc|}
\hline $\begin{array}{c}\text { número } \\
\text { de pacientes }\end{array}$ & $\begin{array}{c}\text { número de } \\
\text { superfícies cariadas }\end{array}$ & percentual \\
\hline 574 & 0 & $89,7 \%$ \\
38 & 1 & $5,9 \%$ \\
15 & 2 & $2,3 \%$ \\
\hline 8 & 3 & $1,3 \%$ \\
3 & 4 & $0,5 \%$ \\
1 & 5 & $0,15 \%$ \\
1 & 7 & $0,15 \%$ \\
640 & 116 & $100 \%$ \\
\hline
\end{tabular}

TABELA 4 - Coeficiente de correlação de Spearman (R) entre incidência de cárie no programa (ICP), número de cáries antes do programa, idade da criança e número de faltas.

\begin{tabular}{ccc|} 
pares de variáveis & valor de $\mathbf{r}$ & $\mathbf{p}$ \\
\hline ICP X cáries antes & 0,12 & $\mathbf{0 , 0 0 ^ { * }}$ \\
ICP X idade & $-0,13$ & $\mathbf{0 , 0 0 ^ { * }}$ \\
ICP X faltas & $-0,06$ & 0,12 \\
\hline
\end{tabular}

${ }^{*} p<0,05$.

um convite à experimentação de novos sabores e, nesse contexto, a tentativa dos pais em limitar essas experiências torna-se praticamente impossível, levando muitas vezes a situações estressantes dentro do ambiente familiar. Além disso, a deficiência da escovação e uso do fio dental, numa fase em que
TABELA 2 - Resultados de média, valor mínimo e valor máximo para as variáveis estudadas somente em crianças com experiência de cárie.

\begin{tabular}{|c|c|c|c|}
\hline variável & média & $\min$. & $\max$. \\
\hline $\begin{array}{l}\text { idade da criança no início } \\
\text { do programa (em meses) }\end{array}$ & 99,33 & 30 & 196 \\
\hline $\begin{array}{l}\text { número de faces cariadas ao ingres- } \\
\text { sar no programa (por paciente) }\end{array}$ & 9,61 & 1 & 63 \\
\hline $\begin{array}{c}\text { número de faces cariadas detectadas } \\
\text { durante o programa (por paciente) }\end{array}$ & 0,25 & 0 & 7 \\
\hline $\begin{array}{c}\text { incidência de faces cariadas } \\
\text { antes do programa/ano }\end{array}$ & 1,61 & 0,08 & 24 \\
\hline $\begin{array}{c}\text { incidência de faces cariadas } \\
\text { durante o programa/ano }\end{array}$ & 0,04 & 0 & 1,57 \\
\hline $\begin{array}{l}\text { tempo (meses) de } \\
\text { permanência no programa }\end{array}$ & 52,92 & 12 & 156 \\
\hline número de faltas/ ano & 0,61 & 0 & 2,83 \\
\hline
\end{tabular}

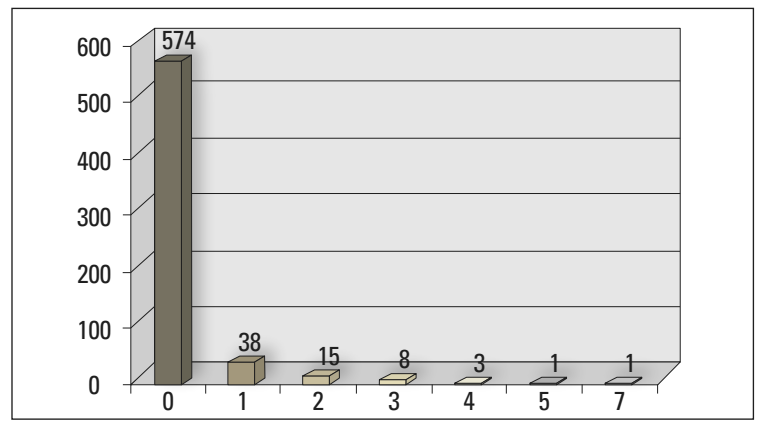

GRÁFICO 1 - Número de pacientes X número de superfícies cariadas.

os dentes permanentes estão em irrupção ou com pouca maturação do esmalte, faz da criança nessa faixa etária um grupo de alto risco, devendo-se valer de todos os esforços para implementar uma estratégia de prevenção máxima possível, que possa ser realizada por um período de tempo relativamente longo. Por outro lado, após os 15 anos de idade, a criança que foi conscientizada e treinada para a realização das técnicas de escovação possui condições de realizar uma higiene bucal autossuficiente, além de nessa fase, em geral, todos os dentes permanentes encontrarem-se irrompidos e em oclusão, o que facilita a limpeza. Dessa maneira, considerase a faixa etária dos 3 aos 15 anos como a de maior risco à cárie e mais importante para a prevenção.

A distribuição das crianças da amostra por 
gênero foi ocasional, já que representa o que ocorre no ser humano, e não houve diferença de incidência de cárie entre os gêneros.

O intervalo de tempo para a realização das seções de profilaxia foi, em média, de 30 dias, determinando 12 atendimentos anuais. Esse intervalo de tempo é considerado ideal, quando se considera a relação custo/benefício. Intervalos maiores - como os semestrais, trimestrais ou bimestrais, comumente recomendados - não são suficientes para se obter o melhor resultado na prevenção, visto que, dependendo do desafio cariogênico, aumentariam os riscos de se desenvolver lesões cariosas. Intervalos menores, apesar de serem mais eficientes, tornam-se impraticáveis.

Alguns profissionais questionam a viabilidade da frequência do atendimento profissional mensal, entretanto o sucesso desse programa pode ser comprovado através da pequena incidência de faltas verificada $(0,54$ faltas/ano). Pode-se constatar no levantamento que muitas crianças tiveram uma frequência de $100 \%$ ao longo de 5,8 e 12 anos ininterruptos.

Portanto, a filosofia de prevenção preconizada foi o controle mecânico periódico de placa por meio da profilaxia profissional, que tem uma melhor relação custo/benefício, promovendo um reequilíbrio da biodiversidade da cavidade bucal, diminuindo os efeitos do desafio cariogênico. Esse método é mais eficaz quando comparado ao autocontrole realizado através da escovação dentária ${ }^{6,18}$.

A profilaxia profissional pode ser realizada por meio do uso de diferentes instrumentos, porém o jato de bicarbonato de sódio tem sido mais eficaz na remoção de placa, principalmente em regiões de difícil acesso, como fóssulas e fissuras ${ }^{17,19,22,23,24,26,28,29}$.

Estudos que avaliaram o uso do jato de bicarbonato de sódio em diferentes pacientes - tanto adultos como crianças, com dentes recém-irrompidos, portadores de aparelhos ortodônticos fixos ou com problemas periodontais - demonstraram sua efetividade na remoção de placa e manchas em todas as superfícies dentárias, bem como nas regiões de fóssulas e fissuras ${ }^{19,22,23}$.

Comparando-se a efetividade do uso do jato de bicarbonato de sódio e da taça de borracha ou escova Robinson, associado ou não a pastas profiláticas, foi observado que o jato promoveu uma remoção melhor e em menor tempo $24,26,28,29$.

Já é reconhecida a efetividade do controle mecânico de placa por meio da profilaxia profissional, quando realizada regularmente, em reduzir o

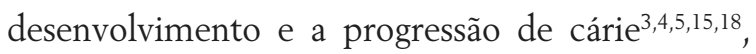
porém, há uma preocupação dos profissionais a respeito dos possíveis danos às estruturas dentárias provocados por esse procedimento.

A aplicação do jato em dentina e cemento expostos, por exemplo, tem sido contraindicada por diversos autores, devido à perda de estrutura dentária ocasionada nestas áreas $1,2,7,8,9,12,17,25$. No entanto, a aplicação do jato de bicarbonato sobre o esmalte dentário hígido parece não ocasionar maiores problemas ${ }^{7,11,12,14,16,20}$. Por outro lado, em esmalte com lesão inicial de cárie, pode haver um desgaste superficial, sendo também esse insignificante ao se levar em consideração a recuperação da estrutura perdida proporcionada pela própria saliva ${ }^{11}$.

Assim, acredita-se que o benefício promovido pelo controle eficiente de placa, produzido pela profilaxia profissional por meio de jato de bicarbonato de sódio, justifica sua aplicação.

Como esse programa foi desenvolvido em clínica particular, onde o compromisso com o paciente foi proporcionar o maior benefício possível em prevenção da cárie, outros métodos foram empregados, procurando agregar valores, porém como métodos coadjuvantes. São eles: controle da dieta, escovação e fio dental, e conscientização e motivação. No entanto, devido à imaturidade e irresponsabilidade da criança, e também pela indisponibilidade dos pais, esses métodos tornam-se ineficientes e impossiveis de serem controlados. Quanto à fluorterapia, mesmo não fazendo parte das estratégias preventivas do programa, esteve presente por meio de dentifrício e água de abastecimento público, mas isto ocorreu em ambos os grupos de 
crianças, antes e durante o programa, não podendo ser responsável pelos resultados encontrados.

O selamento de fóssulas e fissuras com cimentos ionoméricos foi indicado, principalmente, em dentes em irrupção, porém não sistematicamente, não podendo-se tirar nenhuma conclusão quanto à sua contribuição na prevenção, pois não houve nenhum tipo de controle. Pensando em resultados em longo prazo e englobando todos os aspectos que interferem na prevenção, as THDs realizaram sessões de conscientização e motivação, de modo a condicionar a criança para a fase adulta, onde o paciente pode ser autossuficiente. Dessa maneira, o único método considerado indispensável, aplicado e controlado com rigor, foi a profilaxia profissional mensal.

Pelos resultados apresentados na tabela 1, podese observar que a média de idade ao ingressar no programa foi de 7,8 anos. Pode-se considerar essa média alta, devido à pouca informação por parte da população sobre a importância desse tipo de controle. O ideal é que a criança inicie esse controle mensal aos três anos de idade e, assim, os resultados serão ainda melhores.

$\mathrm{Na}$ tabela 1 observamos também que foram detectadas, em média, 5,36 superfícies cariadas no momento do ingresso dessas crianças no programa, ao passo que as lesões de cárie detectadas durante o programa totalizaram uma média de 0,18 . Em números absolutos, esses valores são de 3.430 superfícies cariadas antes e 116 durante o programa.

Esse número pode ser melhor avaliado quando se calcula a incidência de cáries por ano. Para se obter a incidência de cárie ao ingressar no programa, foi dividido o número de cáries iniciais pela idade da criança nesse momento, desconsiderando-se o primeiro ano de vida, período de poucos dentes na cavidade bucal. A incidência de cárie durante o programa foi calculada a partir do número de cáries detectadas após o início do mesmo, dividido pelo tempo de permanência da criança no programa. Com esse cálculo, pode-se observar que a incidência de cáries antes da criança ingressar no programa foi, em média, de 0,9 superfícies cariadas por ano, ao passo que, após o início do programa, esse número foi de 0,03 , o que indica um resultado 30 vezes menor. Em números absolutos, esses valores são de 574 superfícies cariadas antes e 21 depois.

Ao se observar a distribuição dessa incidência ao longo do programa, um fato que chama a atenção é que as superfícies cariadas concentram-se em um pequeno número de crianças, enquanto a grande maioria (89\%) não apresentou novas lesões de cárie.

O teste de correlação indica que aquelas crianças que apresentaram um maior número de cáries antes de ingressar no programa tiveram uma tendência maior ao longo do mesmo $(\mathrm{r}=0,12 ; \mathrm{p}=$ $0,00)$. Isso, provavelmente, deve-se ao fato de que essas crianças encontravam-se diante de um maior desafio cariogênico, devido a seus hábitos alimentares, os quais foram mantidos ao longo do programa. Apesar do índice de cáries dessas crianças, com experiência de cárie, ao ingressarem no programa ter sido maior $(1,61$ superfície cariada por ano), também passou a ser significativamente menor durante o programa, que foi de 0,04 (Tab. 2). Pode-se considerar que a experiência de cárie pouco interfere nos resultados futuros, pois é o reflexo de individualidades que exigiriam uma estratégia mais rígida, não justificada pela insignificante diferença dos resultados encontrados.

Acredita-se que, em nenhum tipo de programa de prevenção da cárie dentária, o zero absoluto é possível de ser alcançado, pelas próprias características do desenvolvimento da lesão, que dependem do desafio cariogênico. Portanto, o objetivo do programa é diminuir os efeitos do desafio cariogênico, pois é impossivel eliminá-lo.

Não houve relação entre o número de faltas e a incidência de cáries, o que indica que duas faltas por ano não interferem nos resultados, o que facilita a implementação do programa.

Em uma de suas publicações sobre o controle da placa, Axelsson e Lindhe ${ }^{3}$ avaliaram a influência de um programa de controle profissional periódico de placa associado a aplicações tópicas 
de flúor nos índices de placa, cárie e gengivite de 192 crianças em fase escolar, de 7 a 14 anos, durante 2 anos. A cada duas semanas, as crianças do grupo teste receberam uma profilaxia profissional associada a um cuidadoso processo de orientação de higiene bucal e aplicação tópica de monoflúor fosfato de sódio a $5 \%$. Os resultados após 1 e 2 anos de experiência mostraram um incremento no histórico de cárie $(0,1$ por ano), ao passo que os indivíduos do grupo que fazia apenas escovação supervisionada mensalmente desenvolveram uma média de 3,1 novas lesões de cárie por ano. Esses resultados não foram tão satisfatórios se comparados aos do presente trabalho, que foram $300 \%$ ou 3 vezes mais eficientes, provavelmente pelas técnicas de profilaxia profissional empregadas naquela época, além do período de controle de 2 anos ser curto para avaliar a incidência de cárie em populações.

O controle mecânico deve buscar a remoção de $100 \%$ da placa, caso contrário, as áreas que permaneceram com placa podem ficar sem controle por meses ou até anos, proporcionando condições de desenvolver uma lesão de cárie.

Já os trabalhos de Axelsson, Lindhe e Nystrom ${ }^{4}$ referem-se a uma estratégia de acompanhamento com profilaxia profissional para adultos. Por esse motivo, não pode ser comparado com os resultados do presente trabalho, devido ao risco à cárie ser completamente diferente em crianças.

Não existem na literatura, até o momento, trabalhos com resultados semelhantes aos aqui apresentados, quanto: ao índice alcançado, à amostra (que foi de crianças de 3 a 15 anos), ao período de acompanhamento e, também, quando comparado a qualquer outro método de prevenção.

Toda estratégia preventiva deve buscar o equilíbrio biológico, mantendo a qualidade de vida do ser humano, e aquela que mais preenche esses requisitos é o controle mecânico da placa bacteriana.

\section{CONCLUSÃO}

Conclui-se, assim, que esse parece ser o caminho mais curto para resolver o problema da cárie dentária, ou seja, o controle mecânico da placa bacteriana dentária através da profilaxia profissional mensal, pois é um método de prevenção possível de ser aplicado em qualquer criança, independentemente de suas condições psicomotoras e sociais, e que proporciona a melhor relação custo-benefício, além de estar de acordo com os conceitos mais atuais de cárie e de seus fatores etiológicos.

\title{
Dental caries prevention program based on the mechanical control of the bacterial plaque in children, through the periodic professional prophylaxis. Results after 25 years of attendance
}

\begin{abstract}
Aim: This study investigated the incidence of dental caries in a prevention program applied for 25 years. Methods: A total of 640 children of both genders aged 3 to 15 years old participated in the program, which was based on mechanical plaque control by professional prophylaxis with sodium bicarbonate jet on a monthly basis. The incidence of dental caries was investigated by clinical and radiographic examination during attendances. Results: Upon inclusion in the program, the mean age of children was 7.8 years; the mean number of decayed tooth surfaces was 5.3 at the onset and 0.18 at completion of the program. The caries incidence per year was 0.9 surface before the program and 0.03 surface during the program. Children were followed-up in the program for a mean period of 52.68 months, with a mean absence of 0.5 per year. These results demonstrate the success of the program, mainly because it attempts to balance the biodiversity in the oral cavity without the risk of undesirable side effects. Conclusions: In conclusion, this seems to be the shortest way to solve the program of dental caries, i.e., mechanical plaque control by monthly professional prophylaxis, since this method may be applied to any child, regardless of the psychomotor and social conditions; it provides the better cost-benefit relationship and agrees with the newest concepts of dental caries and its etiologic factors.
\end{abstract}

Keywords: Caries prevention. Caries prevention program. Regular professional prophylaxis. 


\section{REFERÊNCIAS}

1. AGGER, M. S.; HÖSTED-BINDSLEV, P.; HOVGAARD, O. Abrasiveness of an air-powder polishing system on root surfaces in vitro. Quintessence Int., Berlin, v. 2, no. 5 p. 407-411, May 2001.

2. ATKINSON, D. R. et al. The effect of an air-powder abrasive system on in vitro root surfaces. J. Periodontol., Chicago, v. 55 , no. 1 , p. 13-18, Jan. 1984

3. AXELSSON, P.; LINDHE, J. The effect of a preventive programme in dental plaque, gingivitis and caries in schoolchildren: results after one and two years. J. Clin. Periodontol., Copenhagen, v. 1, no. 2, p. 126-138, 1974.

4. AXELSSON, P.; LINDHE, J.; NYSTROM, B. On the prevention of caries and periodontal disease: results of a 15 year longitudinal study in adults. J. Clin. Periodontol., Copenhagen, v. 18, no. 3, p. 182-189, Mar. 1991.

5. AXELSSON, P.; LINDHE, J.; WÄSEBY, J. The effect of various plaque control measures on gingivitis and caries in schoolchildren. Community Dent. Oral Epidemiol. Copenhagen, v. 4, no. 6, p. 232-239, Nov. 1976

6. BELLINI, H. T.; ARNEBERG, P.; VON DER FEHR, R. Oral hygiene and caries: a review. Acta Odontol. Scand., Oslo, v. 39 , no. 5 , p. 257-265, 1981.

7. BOYDE, A. Airpolishing effects on enamel, dentine, cement and bone. Br. Dent. J., London, v. 156, no. 8, p. 287-291, Apr. 1984.

8. CHRISTENSEN, R. P.; BANGERTER, V. W. Immediate and longterm in vivo effects of polishing on enamel and dentin. J. Prosthet. Dent., St. Louis, v. 57, no. 2, p. 150-160, Feb. 1987.

9. DAVIS, W. B.; WINTER, P. J. Measurement in vitro of enamel abrasion by dentifrice. J. Dent. Res., Alexandria, v. 55, no. 6, p. 970-975, Nov./Dec. 1976

10. FEJERSKOV, O. Concepts of dental caries and their consequences for understanding the disease. Community Dent. Oral Epidemiol., Copenhagen, v. 25, no. 1, p. 5-12, Feb. 1997.

11. FRAGA, A. C. A. Avaliação in vitro do efeito da profilaxia com jato de bicarbonato de sódio sobre o esmalte hígido e com lesão de cárie artificial e posterior remineralização. 2005. Dissertação (Mestrado)-Faculdade de Odontologia de Bauru, Universidade de São Paulo. Bauru, 2005.

12. GALLOWAY, S. E.; PASHLEY, D. H. Rate removal of root structure by use of the Profy-Jet device. J. Periodontol., Chicago, v. 58, no. 7, p. 464-469, July 1987.

13. GELHARD, T. B. F. M.; TEN CATE, J. M.; ARENDS, J. Rehardening of artificial enamel lesions in vivo. Caries Res., Basel, v. 13, no. 1, p. 80-83, Jan./Feb. 1979.

14. GERBO, L. R. et al. Enamel roughness after air powder polishing. Am. J. Dent., St. Louis, v. 6, no. 2, p. 96-98, Apr. 1993.

15. HOLMEN, L. et al. The effect of regular professional plaque removal on dental caries in vivo: a polarized light and scanning electron microscope study. Caries Res., Basel, v. 22, no. 4, p. 250-256, 1988.
16. HONÓRIO, H. M.; RIOS, D.; ABDO, R. C. C.; MACHADO, M. A. A. M. Effect of different prophylaxis methods on sound and demineralized enamel. J. Appl. Oral Sci., Bauru, v. 14, no. 2, p. 117-123, 2006.

17. HOSAYA, Y.; JOHNSTON, J. W. Evaluation of various cleaning and polishing methods on primary enamel. J. Pedod., Boston, v. 13 , no. 3, p. 253- 269,1989

18. LIMA, J. E. O. Um plano de prevenção para consultório odontopediátrico. Rev. Gaúcha Odontol., Porto Alegre, v. 40, n. 6, p. 395-399, nov./dez. 1992.

19. LIMA, S. N. M.; VERRI, R. A. Efeitos da aplicação do bicarbonato de sódio sob pressão no tratamento básico periodontal e na remoção de placa bacteriana. Rev. Paul. Odontol., São Paulo, v. 6, n. 1, p. 2-10, jan./fev. 1984

20. MARTA, S. N.; LIMA, J. E. O.; VONO, B. G.; SILVA, S. M. B. Avaliação qualitativa do efeito do jato de bicarbonato de sódio no esmalte de dentes permanentes jovens. Salusvita, Bauru, v. 18, n. 1, p. 69-77, 1999.

21. MARTA, S. N.; LIMA, J. E. O.; VONO, B. G.; SILVA, S. M. B.; MACHADO, M. A. A. M.; PIN, M. L. G. Effect of professional cleaning and dental brushing with or without fluoridated dentifrice on enamel remineralization. J. Appl. Oral Sci., Bauru, v. 13, no. 3, p. 222-226, 2005.

22. NUTTI SOBRINHO, A. et al. Estudo da ação do sistema Profident sobre a placa bacteriana em bandas ortodônticas através de microscopia eletrônica de varredura. Rev. Paul. Odontol., São Paulo, v. 8, n. 3, p. 10-17, maio/jun. 1986.

23. NUTTI SOBRINHO, A.; LIMA, S. N. M.; WATANABE, I. Estudo da ação do sistema Profident sobre a placa bacteriana através de microscopia eletrônica de varredura. Rev. Paul. Odontol., São Paulo, v. 7, n. 2, p. 34-59, mar./abr. 1986.

24. RAMAGLIA, L. et al. A clinical comparison of the efficacy and efficiency of two professional prophylaxis procedures in orthodontic patients. Eur. J. Orthod., Oxford, v. 21, no. 4, p. 423-428, Aug. 1999.

25. STOOKEY, G. K. In vitro estimates of enamel and dentin abrasion associated with a prophylaxis. J. Dent. Res., Basel, v. 57 , no. 1, p. 36 , Jan. 1978

26. STRAND, G. V.; RAADAL, M. The efficiency of cleaning fissures with an air-polishing instrument. Acta Odontol. Scand., Oslo, v. 46, no. 2, p. 113-117, Apr. 1988

27. TENUTA, L. M. A.; LIMA, J. E. O.; CARDOSO, C. L.; TABCHOURY, C. P. M.; CURY, J. A. Effect of plaque accumulation and salivary factors on enamel demineralization and plaque composition in situ. Pesqui. Odontol. Bras., São Paulo, v. 17, n. 4, p. 326-331, 2003.

28. WEAKS, L. M. et al. Clinical evaluation of the Prophy-Jet as an instrument for routine remove of tooth stain and plaque. J. Periodontol., Chicago, v. 55, no. 8, p. 486-488, Aug. 1984.

29. WILLMANN, D. E.; NORLING, B. K.; JONHSON, W. N. A new prophylaxis instrument: effect on enamel alterations. J. Am. Dent. Assoc., Chicago, v. 101, p. 923-925, Dec. 1980.
Enviado em: junho de 2007

Revisado e aceito: agosto de 2007

Endereço para correspondência

José Eduardo de Oliveira Lima

Al. Octávio Pinheiro Brisola, 9-75

CEP: 17.012-901 - Bauru / SP

E-mail: jeduardo895@terra.com.br 